\title{
Понятие добросовестности в языке российского права: история и современность
}

\author{
Л. В. Попова \\ Челябинский государственный университет, Миасский филиал \\ 456313, Челябинская область, Миасс, пос. Строителей, ул. Керченская д. 1. \\ E-mail: mila fil@mail.ru
}

В статье отражено диахроническое исследование влияния национальных социально-этических ценностей на правовую сферу, что позволяет проследить развитие морально-правовых представлений в русской культуре. Язык юридической коммуникации изучается как объективное отражение юридического сознания. Предметом исследования являются способы номинации понятия добросовестности в языке российского права. Произведена сплошная выборка соответствующих юридических номинаций из кодексов, законодательных и других актов. Обнаружена недостаточная терминологическая определенность данных номинаций как в законодательстве, так и в специальной энциклопедической литературе. С учетом общеязыковой семантики и контекстуального анализа отмечено совмещение в понятии добросовестности социально-этической и юридической семантики, показана его близость с родовым понятием правомерности. Реконструирована история развития номинативной группы с центром «совесть» в русском законодательстве с XVIII века. Выполнен лингвокогнитивный анализ, показана трансформация семантической структуры номинаций и их когнитивного содержания в современном русском юридическом сознании: зафиксировано уменьшение значимости концепта «совесть» и возрастание значимости концепта «закон» при характеристике правомерности. Выполнен лингвокультурологический анализ, определен аксиологический статус понятия добросовестности в истории и современности русского права. Выявлены признаки этнокультурной идентичности юридического языкового сознания в истории и современности. Отмечена этнокультурная значимость этического концепта «совесть», его историческая связь с концептами «душа», «добро», «справедливость», «правда», «честность». Реконструирован этнокультурный образ добросовестного субъекта права, транслируемый русскими законодательными текстами на протяжении нескольких веков. Апелляция к данному образу рассмотрена как компонент речевой стратегии комплексного воздействия на логическую, эмоциональную и ценностно-мотивационную сферы сознания субъекта права. Выявлен коммуникативнопрагматический риск при совмещении исходного социально-этического и производного правового значения добросовестности (эффект недостаточной точности правовых предписаний).

Ключевые слова: добросовестность, правомерность, концепт «совесть», концепт «закон», русское юридическое языковое сознание.

Language of Law

\section{Concept of good faith in the language of the Russian Law: history and present}

Popova L.V.

Miass Branch, Chelyabinsk State University

456313, Chelyabinsk Region, Miass, pos. Stroitelej, Kerchenskaya St. 1,

E-mail: mila fil@mail.ru 
The article discusses the diachronic study of influence of national social and ethical values on the legal sphere. It allows to track development of moral and legal representations in the Russian culture. The language of the legal communication is learned as the objective reflection of the legal consciousness. The object of the research is the ways of the nomination of the concept of good faith in the language of the Russian law. There has been made a continuous sampling of the corresponding legal nominations from the codes, legislative and other acts. There has been discovered insufficient terminological definition of these nominations both in the legislation, and in special encyclopedic literature. The overlap of social-ethical and legal semantics in the concept of good faith is noted basing on common-language semantics and the contextual analysis, its proximity with the generic concept of legitimacy is shown. The history of development in the Russian legislation of the nominative group with «sovest» nucleus is reconstructed from the 18th century on. The linguo-cognitive analysis is made, the transformation of semantic structure of the nominations and their cognitive contents in the modern Russian legal consciousness is shown: decrease of the importance of the concept «conscience» and increase of the importance of the concept «law» is fixed in the semantics of legitimacy. The linguoculturological analysis is made, the axiological status of the concept of conscientiousness in the history and the present of the Russian right is defined. The signs of the ethnocultural identity of legal language consciousness in history and the present are revealed. The ethnocultural importance of the ethical concept «conscience», its historical link to concepts «soul», «good», «justice», «truth», «honesty» is noted. The ethnocultural image of the conscientious legal entity communicated by the Russian legislative texts throughout several centuries is reconstructed. The employment of this image is considered as the component of the speech strategy of integral impact on logical, emotional and belief spheres of the consciousness of a legal entity. There has been revealed the communicative-pragmatic risk when combining initial social-ethical meaning of good faith and its derivative for the legal sphere (effect of the insufficient accuracy of the legal instructions).

Key words: good faith, legitimacy, concept of «conscience», concept of «law», Russian legal language consciousness.

Многие понятия, выраженные терминами современного права, имеют оценочный характер, среди них существует ряд единиц юридического сознания, которые выражаются лексическими средствами, составляющими номинативное поле этнокультурных этических концептов. Присутствие в логико-семантическом пространстве права национально-специфичных понятий и соответствующих им терминов свидетельствует об этнокультурной идентичности юридического сознания. Признавая язык юридической коммуникации достаточно объективным отражением юридического сознания, мы с помощью лингвистических методов выполняем диахроническое исследование влияния социально-этических ценностей на правовую сферу, что позволяет проследить развитие морально-правовых представлений в русской культуре.

В современном юридическом дискурсе регулярно используется номинативная группа с лексемами (не)добросовестный, -о, -ость. В кодексах, законодательных актах, распорядительных документах и других подзаконных актах функционируют составные термины и устойчивые юридические выражения, например: $\partial$. приобретатель (ГК РФ, ч. 1, ст. 147.1; УПК РФ от 18 декабря 2001 г. № 174-ФЗ, ст. 166, п. 2; ФЗ от 22 апреля 1996 г. № 39 Ф3 «О рынке ценных бумаг», ст. 2; Ф3 от 13 июля 2015 г. № 218-Ф3 «О государственной регистрации недвижимости», ст. 68, п. 1), недобросовестный поставщик / подрядчик / исполнитель (ФЗ от 5 апреля 2013 г. № 44-Ф3 «О контрактной системе в сфере закупок товаров, работ, услуг для обеспечения государственных и муниципальных нужд», ст.104), д. / нед. конкуренция (ФЗ от 9 июля 1999 г. № 160-ФЗ «Об иностранных инвестициях в Российской Федерации», ст. 18; ФЗ от 4 декабря 2007 г. № 329-ФЗ «О физической культуре и спорте в Российской Федерации», ст. $20.1 ;$ Ф3 от 25 декабря 2008 г. № 273-Ф3 «О противодействии коррупции», ст. 7, п. 12; Ф3 от 5 апреля 2013 г. № 44-Ф3 «О контрактной системе в сфере закупок товаров, работ, услуг для обеспечения государственных и муниципальных нужд», ст. 8, ч. 2), д. / нед. реклама (ФЗ от 13 марта 2006 г. № 38-ФЗ «О рекламе», ст. 1), д. супруг (СК РФ от 29 декабря 1995 г. № 223-Ф3, ст. 30, п. 4), д. пользоваться правами (АПК РФ от 24 июля 2002 г. № 95-ФЗ, ст. 41, п. 2; ФЗ от 26 июля 2006 г. № 135-ФЗ), д. исполнять обязанности / работать (ТК РФ от 30 декабря 2001 г. № 197-ФЗ, ст. 21; ФЗ от 30 ноября 2011 г. № $342-Ф 3$ «О службе в органах внутренних дел Российской Федерации и внесении изменений в отдельные законодательные акты Российской Федерации», ст. 13, ч. 1, п. 7; ФКЗ от 21 июля 1994 г. № 1-ФКЗ «О Конституционном Суде Российской Федерации», ст. 10; КоАП РФ от 30 декабря 2001 г. № 195-Ф3, ст. 32.13, п. 5); добросовестность / принцип д. / презумпция д. (ЖК РФ от 29 декабря 2004 г. № 188-ФЗ, ст. 7, п. 2; Ф3 от 26 октября 2002 г. № 127-Ф3 «О несостоятельности (банкротстве)», ст. 20, п. 4; ФЗ от 25 декабря 2008 г. № 273-Ф3 «О противодействии коррупции», ст. 7, п. 12; Ф3 от 28 декабря 2009 г. № 381-ФЗ «Об основах государственного регулирования торговой деятельности в Российской Федерации», ст. 12, п. 1; Ф3 от 26 декабря 2008 г. № 294-Ф3 «О защите прав юридических лиц и индивидуальных предпринимателей при осуществлении государственного контроля (надзора) и муниципального контроля», ст. 3, п. 2).

Обобщенное значение в юридическом употреблении имеет лексема добросовестность (одиночная и в составе терминов принцип д. / презумпция д.). В энциклопедии права приведено определение устойчивой номинации добросовестность, разумность и справедливость: наиболее общий принцип российского гражданского права 
используемый для определения пределов допустимого осуществления субъектами гражданского права принадлежащих им гражданских прав, а также для восполнения возможных пробелов в законодательстве (при отсутствии прямого регулирования конкретной ситуации законом, соглашением сторон, обычаями делового оборота и при невозможности использования закона и права по аналогии) [Большая..., 2010: 204]. Юридические энциклопедии фиксируют специальное значение прилагательного добросовестный в составном термине д. приобретатель - лицо, которое приобрело к.-л. имущество и в момент приобретения не знало и не могло знать о существовании прав третьих лиц на это имущество, если не доказано иное [Большая..., 2010: 204; Тихомирова 1997: 119]. Данная дефиниция характеризует законопослушность субъекта в гражданских правоотношениях, указывая на отсутствие намерения нарушить чьи-либо права и юридические нормы в целом. Другие составные термины, выделенные нами в нормативно-правовых актах, не отражены в специальных энциклопедиях. Их значение можно определить по аналогии с термином д. предприниматель, исходя из дистрибуции в тексте и с учетом общеязыковой семантики лексем-компонентов: добросовестный - 'честно, тщательно выполняющий свои обязательства, обязанности' [Словарь..., 1954: 847], добросовестность - 'честность, аккуратность' [Словарь..., 1954: 848]. Например, добросовестная конкуренция - 'честная, не нарушающая права других субъектов и юридические нормы в целом', недобросовестный поставщик - 'не выполняющий свои обязательства, нарушающий права других субъектов и юридические нормы в целом' и т. д. Следует обратить внимание и на то, что в подзаконных актах между честный (-о) и добросовестный (-о) наблюдаются логико-семантические отношения тождественности (честная конкуренция - Приказ Федеральной службы по труду и занятости от 13 января 2017 г. № 13 «Об утверждении Плана деятельности Федеральной службы по труду и занятости, включая реализацию приоритетных проектов, на 2017 год») и комплементарности (честно и добросовестно исполнять обязанности судьи - ФКЗ от 21 июля 1994 г. № 1 -ФКЗ «О Конституционном Суде Российской Федерации», ст. 10).

Сопоставление выявленных профессиональных номинаций позволяет установить, что вследствие функционирования в юридическом дискурсе их семантическая структура усложняется: к социально-этическим семам '(не)честный', '(не)усердный', '(не)ответственный' добавляется сема '(не)правомерность' / '(не)законопослушность' (в зависимости от указания на субъект, объект, действие). Обобщая приведенные факты, можно установить, что в юридическом дискурсе социально-этические номинации, включенные в сферу концепта «совесть», являются регулярным средством оценки и моделирования правомерного поведения, но выражаемые ими понятия не отождествляются с понятием правомерности (сфера концепта «закон»), то есть данные номинации выполняют особую функцию. Комплексный диахронический лингвокогнитивный и лингвокультурологический анализ проясняет соотношение морального и юридического значений, служит для реконструкции историко-культурного пути концепта «совесть» в русском юридическом языковом сознании.

В юридическом дискурсе функционирование номинативной группы с центром совесть выявлено нами с XVIII в. В кодексе Петра I «Уставъ Воинскій» 1716 г. [Полное собраніе... 1830: т. V, № 3006] (здесь и далее знаком № обозначается порядковый номер документа в издании - Л.П.), получившем применение в различных отраслях российского права, при описании правил судебных заседаний и обязанностей судей использован оборот «напамятовать свою совьсть при отправленіи дьла» (раздел «Краткое изображеніе Процессовъ или Судебныхъ тяжебъ», гл. І «О судь и судіяхъ», п. 10). Формула, судя по отбору языковых средств, носит оценочный характер, ее объективным содержанием является обязанность действовать в рамках законов при рассмотрении дела и вынесении приговора. При этом самого термина закон и его производных в контексте нет (предположительно: «соблюдать законы при отправлении дела» и т.п.), то есть нравственный концепт «совесть» эксплицитен, а правовой концепт «закон» имплицитен. Далее в «Уставе» приведен текст судейской присяги (п. 13), в котором актуализированы термины со значением 'закон' (нормативно-правовой акт), и вновь в официальную формулу введен морально-оценочный компонент с комплементарной функцией: «по воинскимъ пунктамъ, правамъ и уставамъ приговаривать и осуждать право (т.е. правомерно) и нелицемьрно». Нелицемерно, имея сему 'честный' (лицемерный - 'скрывающий под видом добродетели пороки, притворяющийся добродетельным, набожным' [Словарь..., 1792: III, 1197]), входит в номинативное поле концепта «совесть». Данный концепт эксплицирован и при регламентации поведения отдельного субъекта права в роли свидетеля: «6. <...> понеже когда онъ присягалъ, тогда уже присяги своей, развь забывъ свою совьсть, не нарушитъ, но толь паче правду донесетъ <...> (гл. III «О свидьтеляхъ»).

Экспликация концепта «совесть» наблюдается в законодательстве Екатерины ІІ. В комплексном нормативноправовом акте «Учрежденія для управленія Губерній Всероссійскія Имперіи» 1775 г. [Полное собраніе... 1830: т. XX, № 14392], установившем новую организацию региональной исполнительной и судебной власти, дана развернутая характеристика необходимых качеств судьи, среди номинаций которых первое место занимало прилагательное совестный: «63. Въ Судьи Совьстнаго Суда Намьстничества (Губерніи) опредьляется выборомъ каждаго Судебнаго мьста той Губерніи, одинъ къ тому способный, совьстный, разсудительный, справедливый и безпорочный человькъ <...>. Основополагающее качество человека с устойчивыми моральными принципами (поступающего согласно совести) предполагает стремление к справедливости (справедливый - 'поступающий по правде, любящий правду' [Словарь..., 1792: IV, 1045]) и отсутствие пороков, неспособность к порицаемым поступкам (беспорочный - 'не имеющий порока' [Словарь..., 1792: V, 132]). Объективным содержанием указанной оценочной формулы является необходимость законопослушности судьи. Как и в законодательстве Петра І, эксплицитен концепт «совесть» (наряду со «справедливость»), имплицитен концепт «закон».

Законодательство XIX в. Александра II развивает форму экспликации концепта «совесть». «Уставъ уголовного судопроизводства» 1864 г. [Полное собраніе... 1830-1884: т. XXXIX, № 41476, 41477] содержит несколько статей, в 
которых оценка неправомерности выражена с помощью сложного деривата недобросовестный (-о). Недобросовестным названо ложное, незаконное обвинение: «121. По признаніи обвиняемаго невиннымъ, Мировой Судья немедленно отпускаетъ его. Если обвиненіе было недобросовьстное, то Судья приговариваетъ обвинителя къ уплать судебныхъ издержекъ, а, въ случаь просьбы обвиняемаго, и къ вознагражденію его за понесенные убытки» (аналогично в ст. 194); «782. На лицо, возбудившее судебное пресльдованіе всльдствіе понесеннаго имъ вреда или убытка, взысканіе вознагражденія оправданному подсудимому обращается лишь тогда, когда лицо это дьйствовало недобросовьстно, искажая обстоятельства происшествія, дьлая ложные показанія или подговаривая къ тому другихъ, или же употребляя иныя незаконныя или предосудительныя средства»; «783. Оправданный подсудимый не лишается права искать вознагражденія и съ должностныхъ лицъ, въ томъ числь съ Судебнаго Сльдователя и Прокурора, если можетъ доказать, что они дьйствовали пристрастно, притьснительно, безъ законнаго повода или основанія, или же вообще недобросовьстно». Следует отметить отношения смыслового тождества и комплементарности между недобросовестный и незаконный, в частности в формулировках «действовать недобросовестно» и «действовать без законного повода», «употреблять незаконные средства» (ст. 782, 783). В ряде статей преобладает термин незаконный (противо-) без аналогичного недобросовестный: незаконное направление дела (ст. 518), противозаконные действия судебных врачей (ст. 490) и др. Сохраняется в «Уставе» и форма предписания правдивости свидетельских показаний с использованием прямой номинации концепта «совесть»: «показать по чистой совьсти» (ст. 98, 99). Таким образом, во второй половине XIX века при квалификации (не)правомерности фактов концепт «совесть» сохраняет актуальность в юридическом сознании, но при этом возрастает частотность экспликации концепта «закон», он начинает доминировать.

Итак, понятие добросовестности, судя по данным юридического дискурса, отражающего юридическое сознание XVIII-XIX вв., было тесно связано с понятием правомерности (сфера концепта «закон»). Для прояснения функции номинативной группы с центром совесть в истории русского юридического сознания необходимо проанализировать значение составляющих группу компонентов. В XVIII в. добросовьстный имело значение ‘праводушный, чистую совьсть наблюдающій'. Данная характеристика давалась, в частности, и субъекту, исполняющему профессиональные обязанности в правоприменительной деятельности, например судье [Словарь... 1792: І, 979]. Исходное совестный - 'сообразующий дела свои с чистой совестью', а также в собственно юридическом употреблении - ‘по совести разбирающий / разбираемый’ (судья, суд) [Словарь... 1792: І, 978]. Существовала также лексема добросовьстіе - ‘праводушіе, добрая совьсть' [Словарь... 1792: І, 979]. Все производные восходят к совьсть 'врожденная души нашея сила или способность судить нравственную доброту или худобу нашихъ деяній; внутреннее увьреніе, твердое признаніе нравственной доброты или худобы дьлъ нашихъ' [Словарь... 1792: І, 979]. Отметим, что в дефинициях совестный и добросовьстный, даже при характеристике представителя судебных органов, семантическим центром было моральное качество - следование внутреннему чувству справедливости. Поскольку академический толковый словарь русского языка XVIII в. дает представление о тезаурусе в целом, выбранные для иллюстрации дефиниций примеры из юридического дискурса, очевидно, демонстрируют одну из наиболее типичных для русского языкового сознания ситуаций, в когнитивной модели которой концепт «совесть» был обязательным. Этнокультурный концепт «совесть» отражает «личное сознание, нравственно оценивающее все проявления добра и зла в единстве чутья и чувства, души и духа, вызывая сочувствие и активное соучастие в общем деле» [Колесов 2014: І, 286]. Добросовестность в традиционном языковом сознании предполагала нравственную упорядоченность духовного мира личности: «порядочность» - «совокупность высоких нравственных качеств, свойственных организованному человеку; включает понятие о чести, достоинстве, добре и справедливости в его душе, объединяя их в личностный “нравственный порядок"» [Колесов 2014: І, 65]. Таким образом, в истории русского языкового сознания у прилагательных совестный, добросовестный дефинитивно была обозначена связь не только с концептом «совесть», но и с концептами «душа», «добро», «справедливость». Данные номинации акцентировали внимание на целостности духовного мира личности, позволяющей человеку выбирать правильную модель поведения и оценивать поведение других по нравственной шкале «хорошо (добро) - плохо (зло)» как в неофициальном, так и в официальном общении. Для юридического языкового сознания XVIII-XIX вв., по-видимому, была характерна интерпретация добросовестности как фундамента правомерности.

K XX в. центром семантической структуры лексем добросовестный, добросовестность становятся признаки честности, усердия, ответственности [Словарь..., 1954: 847, 848]. Акцент в современном осмыслении добросовестности смещен на ее прагматическое значение в социальных и правовых отношениях. Связь с концептом «совесть» (а также «душа» и др.) дефинитивно не эксплицируется, хотя, по-видимому, сохраняется в языковом сознании как фоновая, учитывая прозрачность структуры лексемы. Выявляется когнитивная пропозиция: при наличии внешнего ограничителя, устанавливающего общие правила поведения (формальная обязанность), субъект добровольно выстраивает свое поведение согласно внутреннему императиву, стремясь к достижению идеала социальной роли. Очевидно, эта пропозиция положена в основу современной юридической интерпретации добросовестности. Центральный семантический признак правовой семантики наиболее тесно связан с концептом «честность» и шкалой «правда - ложь»: «честность» - «совокупность безупречных душевных качеств человека чести как высшая ценность, исключающая хитрость, ложь и воровство» [Колесов 2014: I, 488].

Итак, на протяжении нескольких столетий понятие добросовестности остается актуальным для русского юридического сознания. В нормативно-правовых текстах регулярно функционируют номинативные средства экспликации этнокультурного концепта «совесть», соотносимого в юридическом языковом сознании с концептом «закон». Это соотношение менялось исторически. Первоначально добросовестность интерпретировалась как 
фундамент правомерности, что контекстуально отразилось в смысловом сближении профессиональных номинаций типа правый / законный и совестный / добросовестный при доминантности последних. Безусловно, на профессиональное сознание оказывало влияние этнокультурное представление о душе как центре личности, совести как ядре полноценного духовного мира. В дальнейшем у социально-этической модели номинации сужается значение, приоритетной становится связь с концептом «честность» (представление о полезности честного человека для общества), однако окончательного отождествления добросовестности и честности до настоящего времени не наблюдается. В отношении между концептами «закон» и «совесть» усилилась дифференциация.

При доминантности понятия правомерности (законности) понятие добросовестности сохраняет силу эталона в ситуациях недостаточности юридических норм (шкалы «законность - незаконность»), выступая как дополнительный регулятор в правоотношениях (компенсаторная функция). При этом следы прежнего логико-семантического соотношения сохраняются: добросовестно (а не законно) пользоваться правами и т. п. Добросовестность подчеркивает связь юридических норм с социально-нравственными, указывая на значимость индивидуального выбора субъекта права с опорой на моральный «кодекс», на необходимость саморегуляции поведения. С нашей точки зрения, в современном юридическом сознании у понятия добросовестности сохраняется сверхфункция аксиологическая: трансляция этнокультурного образа (добро)совестного человека в целях усиления воздействия юридического текста не только на логическую, но и на эмоциональную и ценностно-мотивационную сферы сознания субъекта права. Данный способ речевого воздействия (совмещение исходного нравственного и производного правового значения) может приводить и к эффекту недостаточной точности правовых предписаний, поскольку верификация добросовестности сложнее, чем собственно законности.

\section{Литература}

1. Большая юридическая энциклопедия / авт.-сост. А. Б. Барихин. М., 2010.

2. Колесов В. В., Колесова Д. В., Харитонов А. А. Словарь русской ментальности: в 2 т. СПб., 2014.

3. Полное собрание законов Российской Империи. Собрание первое. С 1649 по 12 декабря 1825 года. СПб., 1830.

4. Полное собрание законов Российской Империи. Собрание второе. - СПб., 1830-1884.

5. Словарь Академии Российской: в 6 ч. СПб., 1792.

6. Словарь современного русского литературного языка. Т. ІІІ. М.; Л., 1954.

7. Т Тихомирова Л. В., Тихомиров М. Ю. Юридическая энциклопедия / под ред. М. Ю. Тихомирова. М., 1997.

\section{References}

1. Big Legal encyclopedia. (2010). [Bolshaya yuridicheskaya ehnciklopediya]. A. B. Barikhin (Ed.). Moscow (in Russian).

2. Complete collection of laws of the Russian Empire. The First collection. From 1649 to December 12, 1825. (1830). [Polnoe sobranie zakonov Rossijskoj Imperii. Sobranie pervoe. S 1649 po 12 dekabrya 1825 goda]. St. Petersburg (in Russian).

3. Complete collection of laws of the Russian Empire. The Second collection (1885). [Polnoe sobranie zakonov Rossijskoj Imperii. Sobranie vtoroe]. St. Petersburg (in Russian).

4. Dictionary of Academy Russian. (1792). [Slovar' Akademii Rossijskoj]. St. Petersburg (in Russian).

5. Dictionary of the modern Russian literary language. (1954). [Slovar' sovremennogo russkogo literaturnogo yazyka]. V. III. Moscow; Leningrad (in Russian).

6. Kolesov, V. V., Kolesova, D. V., Haritonov, A. A. (2014). Dictionary of the Russian mentality [Slovar' russkoj mental'nosti]. St. Petersburg (in Russian).

7. Tikhomirova, L. V., Tikhomirov, M. Yu. (1997). The legal encyclopedia [Yuridicheskaya ehnciklopediya]. M. Yu. Tikhomirov (Ed.). Moscow (in Russian).

\section{Citation:}

Попова Л.В. Понятие добросовестности в языке российского права: история и современность// Юрислингвистика.- 2019.-11.-С.19-23.

Popova, L.V. (2019). Concept of good faith in the language of the Russian Law: history and present. Legal Linguistics, 11, 19-23.

(cc) EY This work is licensed under a Creative Commons Attribution 4.0. License 